\title{
Analytical Modeling of Current Harmonic Components in PMSM Drive With Voltage-Source Inverter by SVPWM Technique
}

\author{
Wenyi Liang, Jianfeng Wang, Patrick Chi-Kwong Luk, Senior Member, IEEE, Weizhong Fang, Member, IEEE, \\ and Weizhong Fei, Member, IEEE
}

\begin{abstract}
The sideband current harmonic components would inhere in permanent-magnet (PM) synchronous machine systems driven by a voltage-source inverter with space vector pulsewidth modulation (SVPWM). However, these harmonics could potentially deteriorate the overall performance of the drive system by increasing the resultant losses, torque ripple, and electromagnetic and acoustic noises. The main sideband harmonic voltages and currents in PM synchronous machine driven by voltage-source inverter with SVPWM technique, are analytically derived and expressed in both stator and rotor frame. The experimental results are carried out to underpin the validity of the analytical model. The analytical model could be employed to assess the influencing factors of current harmonics. In addition, it offers insightful guidance to the effective reductions of harmonic losses, torque ripples, and electromagnetic noises.
\end{abstract}

Index Terms-Bessel function, coordinate transformation, permanent-magnet synchronous machine (PMSM), sideband harmonic, space vector pulsewidth modulation (SVPWM).

\section{NOMENCLATURE}

$E_{d} \quad$ Direct current bus voltage.

$i_{d} \quad$ The $d$-axis component of stator current vector.

$i_{q} \quad$ The $q$-axis component of stator current vector.

$i_{s}$ The stator current vector.

$J_{k} \quad$ The $k$ th-order Bessel function.

$L_{d} \quad$ The $d$-axis component of inductance.

$L_{q} \quad$ The $q$-axis component of inductance.

$L_{s} \quad$ Stator inductance.

$M$ Modulation ratio.

$\theta \quad$ The rotor position.

$R_{s} \quad$ The stator resistance.

$T_{s} \quad$ Pulsewidth modulation carrier period.

$u_{s}$ The stator voltage vector.

$u_{d}$ The $d$-axis component of stator voltage vector.

Manuscript received August 19, 2013; revised December 17, 2013; accepted January 27, 2014. Paper no. TEC-00485-2013.

W. Liang was with Hangzhou Easitech Corporation, Hangzhou 310008, China. He is now with the School of Engineering, Cranfield University, Cranfield, MK43 0AL, U.K. (e-mail: w.liang@cranfield.ac.uk).

J. Wang and W. Fang are with Hangzhou Easitech Corporation, Hangzhou 310008, China (e-mail: wangif@easi-tech.com; fangwz@easi-tech.com).

P. C.-K. Luk and W. Fei are with the School of Engineering, Cranfield University, Cranfield, MK43 0AL, U.K. (email: p.c.k.luk@cranfield.ac.uk; w.fei@cranfield.ac.uk)

Color versions of one or more of the figures in this paper are available online at http://ieeexplore.ieee.org. $\mathrm{x}$

$\mathrm{S} x$ $u_{q} \quad$ The $d$-axis component of stator voltage vector.

$\varphi_{0} \quad$ Initial phase of voltage vector.

$\omega_{1}$ Modulation angular speed.

$\omega_{s}$ Carrier angular speed.

\section{INTRODUCTION}

$\mathbf{P}$ ERMANENT-MAGNET synchronous machines (PMSM), with their superior performances over other competing machines, have become the central part of variable frequency drive systems in a host of new applications. In these PMSM drive systems, the space vector pulsewidth modulation (SVPWM) technique is widely employed to achieve excellent static and dynamic performances. However, SVPWM generates undesirable sideband voltage and current harmonics during the intrinsic switching process. These harmonic frequencies are located nearby the carrier frequency and its multiples. The sideband harmonic components will increase the iron core losses, copper resistive losses, permanent-magnet (PM) eddy current losses, and hence, reduce the operational efficiency of the machine [1]-[3]. In high-power industrial and railway traction applications, the switching frequency of the power devices is severely restricted to mitigate switching losses and adverse effects caused by high $\mathrm{d} u / \mathrm{d} t$. However, this will lead to increased sideband harmonic currents and, hence, torque pulsations in the machine [4], [5]. Furthermore, sideband harmonics in PMSM could also induce ear-piercing high-frequency electromagnetic noise [6], [7]. Such unpleasant acoustic noise is quite a common issue in many different applications, such as electric vehicles and elevators, and should be addressed properly.

To date, there have been a number of analytical studies on sideband voltage harmonics of the motor drives with SVPWM technique. The double Fourier series (DFS) method has been adopted to investigate the voltage harmonic spectrum under SVPWM technique [8]-[10]. Alternatively, the pulsewidth modulation (PWM) signals could be decomposed into series of symmetrical or mirror-symmetrical patterns so that the voltage harmonic spectra of these patterns could be derived [11]. The method of multiple pulses is introduced to analyze the voltage harmonic components of SVPWM [12]. However, the analytical modeling of the sideband current harmonics with SVPWM technique is more complicated and burdensome. Hence, existing studies have mainly focused on the derivation of the sideband current harmonic related coefficients, which can be directly used 
as a quality index. The harmonic distortion rate of the current has been derived by analytically studying the voltage pulse and resulting harmonic current within one pulse period for single phase [13]. Moreover, the peak ripple values of the current in $d$ and $q$ axes can be analytically computed by analyzing the current waveform in one basic inverter cycle [14]. Instead of the current one, the flux harmonic distortion factor (HDF) is analytically developed to evaluate the harmonic distortion in [15], [16]. Furthermore, various methods have been proposed to reduce the sideband harmonic components in PMSM drive with SVPWM technique. A special switching sequence, which involved division of active vector time for SVPWM generation, was used to effectively reduce the current harmonic distortion [17], [18]. Multilevel inverter topologies have been introduced to apply the current harmonic cancellation technique [19], [20]. Besides, random pulse width PWM technique has been implemented to suppress the amplitudes of the sideband current harmonics [21].

As aforementioned, the direct analytical sideband harmonic expressions of current have yet been used for detailed harmonic characteristic analysis. The analytical results could be employed to assess the influence factors of current harmonics, such as operational condition, machine control strategies, and electromagnetic parameters. In addition, it gives insightful guidance to the reductions of harmonic losses, torque pulsations, and electromagnetic noises. Consequently, the current investigation focuses mainly on the direct analytical investigations of the sideband voltage and especially current harmonic components in PMSM powered by voltage-source inverter (VSI) with SVPWM technique. In Section II, the main sideband voltage harmonic components, whose frequencies are located nearby the first and second carrier frequency, are analytically derived in both stator and rotor frames. In Section III, the analytical expressions of the corresponding sideband current harmonic components are developed in rotor and stator frames accordingly. In Section IV, the experimental results are presented to validate analytical models. In Section IV, a prototype interior PMSM is driven by a rotor-flux-oriented vector control strategy with SVPWM technique under different operation conditions and the experimental results are presented to validate analytical models. Concluding remarks are presented in Section V.

\section{Analytical Sideband Voltage Harmonic Modeling}

The analytical modeling of the phase voltage harmonics of PMSM powered by VSI with SVPWM technique can be first derived directly based on Fourier series (FS) analysis in the stator frame. However, it is rather hard to obtain the analytical harmonic current expressions directly from the phase voltage ones later. Consequently, it is very necessary to convert the phase voltage harmonic components to $d$-and $q$-axis ones in the rotor frame by coordinate transformation.

\section{A. Phase Voltage Harmonics in Stator Frame}

The modulation model of the symmetrical sampled SVPWM is shown in Fig. 1, where $y(t)$ is the modulation wave. The output pulse width depends on the value of $y(t)$ at the time

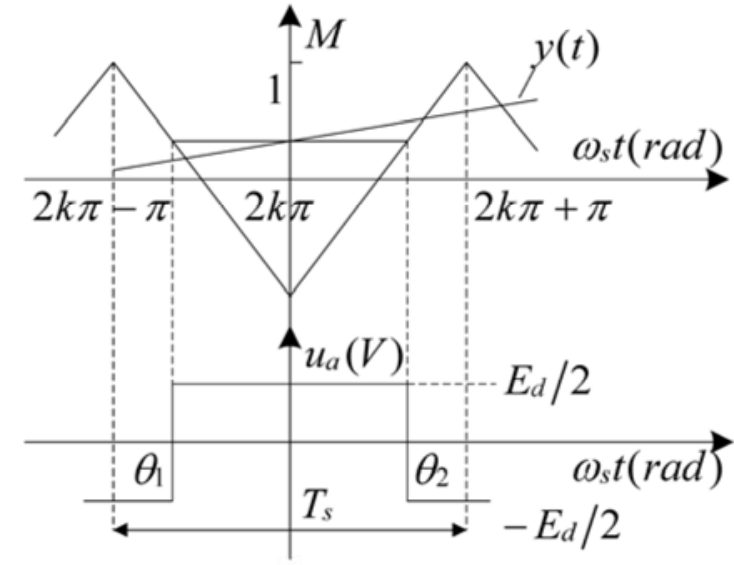

Fig. 1. Symmetrical regular sampled SVPWM.

$t=2 k \pi / \omega_{s}$. It can be obtained from Fig. 1 such that

$$
\theta_{1}=-\frac{\pi(1+y(t))}{2} \quad \text { and } \quad \theta_{2}=\frac{\pi(1+y(t))}{2} .
$$

The phase A output voltage $u_{a}$ can be written as

$$
u_{a}= \begin{cases}-\frac{E_{d}}{2}, & \left(\omega_{1} t \leq \theta_{1}\right) \\ \frac{E_{d}}{2}, & \left(\theta_{1} \leq \omega_{1} t \leq \theta_{2}\right) \\ -\frac{E_{d}}{2}, & \left(\omega_{1} t \geq \theta_{2}\right) .\end{cases}
$$

It is assumed that the zero voltage vectors are divided equally in SVPWM. The modulation wave $y(t)$ can be expressed as

$$
y(t)=\left\{\begin{array}{lc}
\sqrt{3} a \sin \left(\omega_{1} t\right), & 0 \leq \omega_{1} t \leq \frac{\pi}{6} \\
a \sin \left(\omega_{1} t+\frac{\pi}{6}\right), & \frac{\pi}{6} \leq \omega_{1} t \leq \frac{\pi}{2}
\end{array}\right.
$$

where $a$ is the modulation coefficient, $0 \leq a \leq 1$. By applying the Fourier series analysis, $y(t)$ can be rewritten as

$$
y(t)=a\left(\frac{2}{\sqrt{3}} \sin \left(\omega_{1} t\right)+\sum_{k=0}^{\infty} \frac{6 \times(-1)^{k+1}}{\pi\left(1-n^{2}\right)} \sin \left(n \omega_{1} t\right)\right)
$$

where $n=6 k+3, k=0,1,2, \ldots$.When $k \geq 1$, the harmonic coefficients are all very small compared with the fundamental one. Therefore, only the fundamental and third harmonics are considered in the study. The function $y(t)$ can be approximated as

$$
y(t) \approx M\left(\sin \left(\omega_{1} t\right)+\xi \sin \left(3 \omega_{1} t\right)\right)
$$

where

$$
M=\frac{2 a}{\sqrt{3}} \quad \text { and } \quad \xi=\frac{3 \sqrt{3}}{8 \pi} .
$$

The Fourier series analysis based on the frequency $\omega_{1}$ of the modulation wave could not be performed as the pulses are asymmetric in the whole period of the modulation wave. Consequently, Fourier series analysis based on $\omega_{s}$ are carried out 
TABLE I

FIRST CARRIER FREQUENCY SIDEBAND VOLTAGE HARMONIC IN ROTOR FRAME

\begin{tabular}{ccc}
\hline \hline Frequency & Axis & Results \\
\hline$\omega_{s}$ & $d$ & 0 \\
& $q$ & 0 \\
$\omega_{s}+2 \omega_{1}$ & $d$ & $C_{2} \cos \left(\omega_{s} t+3 \omega_{l} t-\varphi_{0}\right)$ \\
& $q$ & $-C_{2} \sin \left(\omega_{s} t+3 \omega_{l} t-\varphi_{0}\right)$ \\
$\omega_{s}-2 \omega_{1}$ & $d$ & $C_{2} \cos \left(\omega_{s} t-3 \omega_{l} t+\varphi_{0}\right)$ \\
& $q$ & $C_{2} \sin \left(\omega_{s} t-3 \omega_{l} t+\varphi_{0}\right)$ \\
$\omega_{s}+4 \omega_{1}$ & $d$ & $C_{4} \cos \left(\omega_{s} t+3 \omega_{l} t+\varphi_{0}\right)$ \\
& $q$ & $C_{4} \sin \left(\omega_{s} t+3 \omega_{l} t+\varphi_{0}\right)$ \\
$\omega_{s}-4 \omega_{1}$ & $d$ & $C_{4} \cos \left(\omega_{s} t-3 \omega_{l} t-\varphi_{0}\right)$ \\
& $q$ & $-C_{4} \sin \left(\omega_{s} t-3 \omega_{l} t-\varphi_{0}\right)$ \\
\hline \hline
\end{tabular}

instead. By considering $u_{a}$ as the even function of $\omega_{s}, u_{a}$ can be rewritten as

$$
\frac{u_{a}}{E_{d} / 2}=\frac{a_{0}}{2}+\sum_{n=1}^{\infty} a_{n} \cos \left(n \omega_{s} t\right)
$$

where

$$
\begin{aligned}
& a_{0}=2 M\left(\sin \left(\omega_{1} t\right)+\xi \sin \left(3 \omega_{1} t\right)\right) \\
& a_{n}=\frac{4}{n \pi} \sin \left(\frac{n \pi}{2}+\frac{M n \pi}{2}\left(\sin \left(\omega_{1} t\right)+\xi \sin \left(3 \omega_{1} t\right)\right)\right) .
\end{aligned}
$$

As for $n \geq 3$, due to the relatively high-frequency and large inductance, the corresponding harmonic currents can be ignored. Thus, only $n=1$ and $n=2$ are analytically investigated in this paper, sufficient, yet simple. By neglecting the high-order Bessel function, $a_{1}$ can be approximated as

$$
a_{1} \approx C_{0}+2 C_{2} \cos \left(2 \omega_{1} t\right)+2 C_{4} \cos \left(4 \omega_{1} t\right)
$$

where

$$
\begin{aligned}
C_{0} & =\frac{4}{\pi} J_{0}\left(\frac{M \pi}{2}\right) J_{0}\left(\frac{M \pi \xi}{2}\right) \\
C_{2} & =\frac{4}{\pi}\left\{J_{2}\left(\frac{M \pi}{2}\right) J_{0}\left(\frac{M \pi \xi}{2}\right)-J_{1}\left(\frac{M \pi}{2}\right) J_{1}\left(\frac{M \pi \xi}{2}\right)\right\} \\
C_{4} & =\frac{4}{\pi} J_{1}\left(\frac{M \pi}{2}\right) J_{1}\left(\frac{M \pi \xi}{2}\right)
\end{aligned}
$$

where $J_{k}$ is a Bessel function of order $k$. Consequently, the sideband harmonic coefficient in the first carrier frequency domain $H_{1}=a_{1} \cos \left(\omega_{s} t\right)$ can be expressed as

$$
\begin{aligned}
H_{1} \approx & C_{0} \cos \left(\omega_{s} t\right)+C_{2} \cos \left(\left(\omega_{s} \pm 2 \omega_{1}\right) t\right) \\
& +C_{4} \cos \left(\left(\omega_{s} \pm 4 \omega_{1}\right) t\right) .
\end{aligned}
$$

Similarly, $a_{2}$ can be approximated as

$$
\begin{aligned}
a_{2} \approx & -2 C_{1} \sin \left(\omega_{1} t\right)-2 C_{3} \sin \left(3 \omega_{1} t\right) \\
& -2 C_{5} \sin \left(5 \omega_{1} t\right)-2 C_{7} \sin \left(7 \omega_{1} t\right)
\end{aligned}
$$

TABLE II

SECOND CARRIER FREQUENCYSIDEBAND VOLTAGE HARMONIC IN ROTOR FRAME

\begin{tabular}{ccc}
\hline \hline Frequency & Axis & Results \\
\hline$\omega_{1}+2 \omega_{s}$ & $d$ & $C_{1} \sin \left(2 \omega_{s} t+\varphi_{0}\right)$ \\
& $q$ & $-C_{1} \cos \left(2 \omega_{s} t+\varphi_{0}\right)$ \\
$\omega_{1}-2 \omega_{s}$ & $d$ & $C_{1} \sin \left(-2 \omega_{s} t+\varphi_{0}\right)$ \\
& $q$ & $-C_{1} \cos \left(-2 \omega_{s} t+\varphi_{0}\right)$ \\
$3 \omega_{1} \pm 2 \omega_{s}$ & $d$ & 0 \\
& $q$ & 0 \\
$5 \omega_{1}+2 \omega_{s}$ & $d$ & $C_{5} \sin \left(2 \omega_{s} t+6 \omega_{1} t-\varphi_{0}\right)$ \\
& $q$ & $C_{5} \cos \left(2 \omega_{s} t+6 \omega_{1} t-\varphi_{0}\right)$ \\
$5 \omega_{1}-2 \omega_{s}$ & $d$ & $C_{5} \sin \left(-2 \omega_{s} t+6 \omega_{1} t-\varphi_{0}\right)$ \\
& $q$ & $C_{5} \cos \left(-2 \omega_{s} t+6 \omega_{1} t-\varphi_{0}\right)$ \\
$7 \omega_{1}+2 \omega_{s}$ & $d$ & $C_{7} \sin \left(2 \omega_{s} t+6 \omega_{1} t+\varphi_{0}\right)$ \\
& $q$ & $-C_{7} \cos \left(2 \omega_{s} t+6 \omega_{1} t+\varphi_{0}\right)$ \\
$7 \omega_{1}-2 \omega_{s}$ & $d$ & $C_{7} \sin \left(-2 \omega_{s} t+6 \omega_{1} t+\varphi_{0}\right)$ \\
\hline \hline
\end{tabular}

where

$$
\begin{aligned}
C_{1}= & -\frac{2}{\pi}\left\{J_{1}(M \pi) J_{0}(M \pi \xi)+J_{2}(M \pi) J_{1}(M \pi \xi)\right. \\
& \left.-J_{4}(M \pi) J_{1}(M \pi \xi)\right\} \\
C_{3}= & -\frac{2}{\pi}\left\{J_{3}(M \pi) J_{0}(M \pi \xi)+J_{0}(M \pi) J_{1}(M \pi \xi)\right\} \\
C_{5}= & -\frac{2}{\pi} J_{2}(M \pi) J_{1}(M \pi \xi) \\
C_{7}= & -\frac{2}{\pi} J_{4}(M \pi) J_{1}(M \pi \xi) .
\end{aligned}
$$

The sideband harmonic coefficient in the second carrier frequency domain, $H_{2}=a_{2} \cos \left(\omega_{s} t\right)$, can be represented as

$$
\begin{aligned}
H_{2} \approx & C_{1} \sin \left(\left(\omega_{1} \pm 2 \omega_{s}\right) t\right)+C_{3} \sin \left(\left(3 \omega_{1} \pm 2 \omega_{s}\right) t\right) \\
& +C_{5} \sin \left(\left(5 \omega_{1} \pm 2 \omega_{s}\right) t\right)+C_{7} \sin \left(\left(7 \omega_{1} \pm 2 \omega_{s}\right) t\right) .
\end{aligned}
$$

\section{B. D and $Q$ Voltage Harmonics in Rotor Frame}

The main phase voltage harmonic components in first and second carrier frequency domains are analytically derived in the last section. Since the three-phase windings are normally symmetric in the machine, the corresponding harmonic voltage components in the other two phases could be directly obtained. The voltage harmonics can be rearranged in rotor frame by Park transformation.

By Park transformation of harmonics from (11), the first carrier frequency sideband voltage harmonics in the rotor frame can be analytically obtained as in Table I. $\varphi_{0}$ is the initial phase of the space voltage vector, which can be expressed as $\varphi_{0}=\pi+\delta$, 
TABLE III

Key PARAMETERS OF THE EXPERIMENTAL PMSM

\begin{tabular}{cccc}
\hline \hline Parameter & Value & Parameter & Value \\
\hline Pole pair number & 4 & DC link Voltage & $24 \mathrm{~V}$ \\
D axis inductance & $27.1 \mathrm{uH}$ & Q axis inductance & $36.8 \mathrm{uH}$ \\
Phase resistance & $5.2 \mathrm{~m} \Omega$ & PM flux linkage & $0.0179 \mathrm{~Wb}$ \\
Rotor inertia & $21.5 \mathrm{~kg} \cdot \mathrm{cm}^{2}$ & Carrier frequency & $4 \mathrm{kHz}$ \\
\hline \hline
\end{tabular}

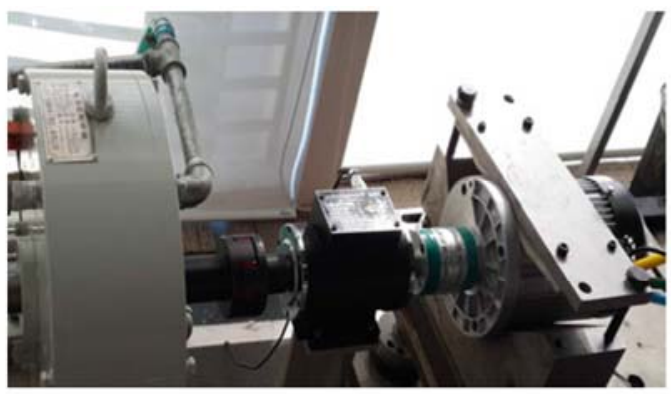

Fig. 2 Experimental step of the PMSM drive system.

where $\delta$ is the toque angle. So, $\varphi_{0}$ can be rewritten as

$$
\varphi_{0}=\pi+\arctan \left|\frac{U_{d}}{U_{q}}\right| .
$$

The results in Table I have shown that only the $\omega_{s} \pm \omega_{1}$ order voltage harmonics exist in the rotor frame. The overall voltage harmonics in rotor frame can be synthesized by all the corresponding axis items in Table I as

$$
\begin{aligned}
& u_{d \omega_{s} \pm 3 \omega_{1}}=U_{d 1} \cos \left(\omega_{s} t \pm 3 \omega_{1} t \pm \varphi_{d 1}\right) \\
& u_{q \omega_{s} \pm 3 \omega_{1}}= \pm U_{q 1} \sin \left(\omega_{s} t \pm 3 \omega_{1} t \pm \varphi_{q 1}\right)
\end{aligned}
$$

where

$$
\begin{aligned}
& U_{d 1}=\sqrt{C_{2}^{2}+C_{4}^{2}+2 C_{2} C_{4} \cos \left(2 \varphi_{0}\right)} \\
& U_{q 1}=\sqrt{C_{2}^{2}+C_{4}^{2}-2 C_{2} C_{4} \cos \left(2 \varphi_{0}\right)}
\end{aligned}
$$

$\varphi_{d 1}$ and $\varphi_{q 1}$ can be determined by

$$
\begin{aligned}
& \cos \varphi_{d 1}=\frac{\left(C_{2}+C_{4}\right) \cos \left(\varphi_{0}\right)}{\sqrt{C_{2}^{2}+C_{4}^{2}+2 C_{2} C_{4} \cos \left(2 \varphi_{0}\right)}} \\
& \sin \varphi_{d 1}=\frac{\left(C_{4}-C_{2}\right) \sin \left(\varphi_{0}\right)}{\sqrt{C_{2}^{2}+C_{4}^{2}+2 C_{2} C_{4} \cos \left(2 \varphi_{0}\right)}} \\
& \cos \varphi_{q 1}=\frac{\left(C_{4}-C_{2}\right) \cos \left(\varphi_{0}\right)}{\sqrt{C_{2}^{2}+C_{4}^{2}-2 C_{2} C_{4} \cos \left(2 \varphi_{0}\right)}} \\
& \sin \varphi_{q 1}=\frac{\left(C_{2}+C_{4}\right) \sin \left(\varphi_{0}\right)}{\sqrt{C_{2}^{2}+C_{4}^{2}-2 C_{2} C_{4} \cos \left(2 \varphi_{0}\right)}} .
\end{aligned}
$$

It can be observed from (16) to (18) that the main components of the voltage harmonics of first carrier frequency domain in the rotor frame are the $\omega_{s} \pm \omega_{1}$-order ones, and their amplitudes are determined by both the modulation ratio and torque angle. By a similar process, the second carrier frequency sideband

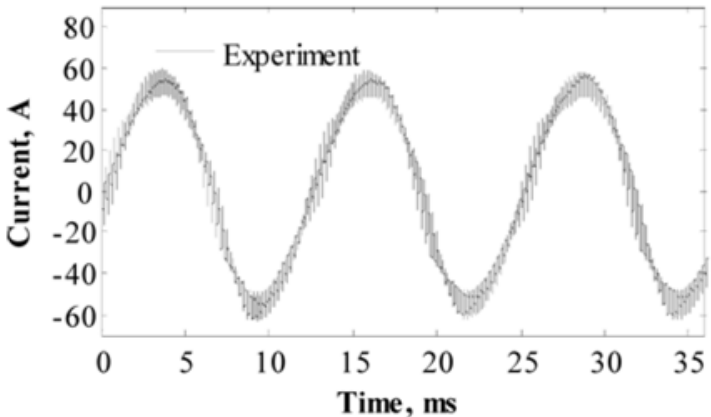

(a)

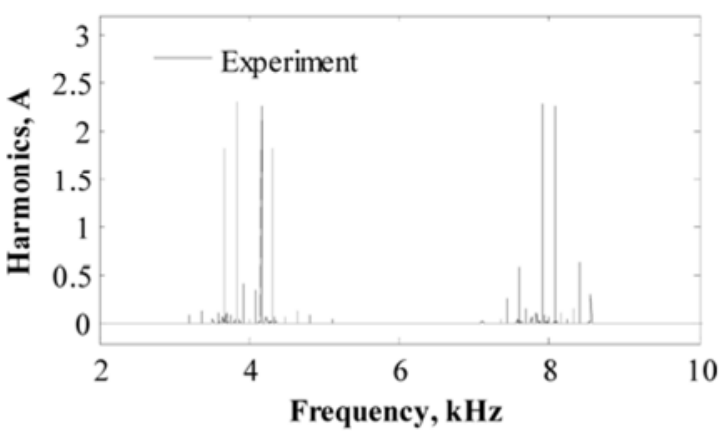

(b)

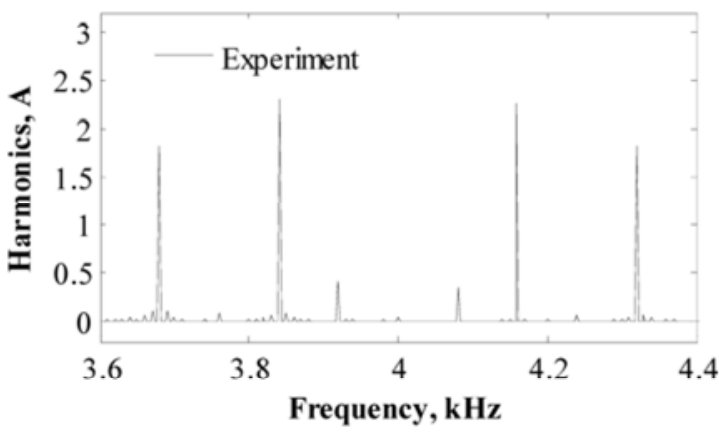

(c)

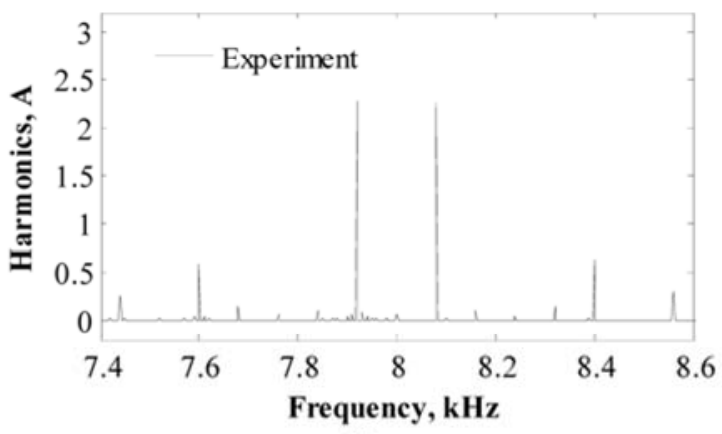

(d)

Fig. 3. Experimental phase current waveform and its harmonic spectrum of the PMSM under $5 \mathrm{~N} \cdot \mathrm{m}$ load and $1200 \mathrm{r} / \mathrm{min}$ : (a) phase current waveform, (b) current harmonic spectrum, (c) first carrier frequency sideband harmonics, and (d) second carrier frequency sideband harmonics.

voltage harmonics in the rotor frame can be analytically derived and given in Table II.

It can be observed from the Table II that only the $2 \omega_{s}$ - and $2 \omega_{s} \pm 6 \omega_{1}$-order voltage harmonics exist for the second carrier frequency sideband harmonics in the rotor frame. The $2 \omega_{s}$-order 


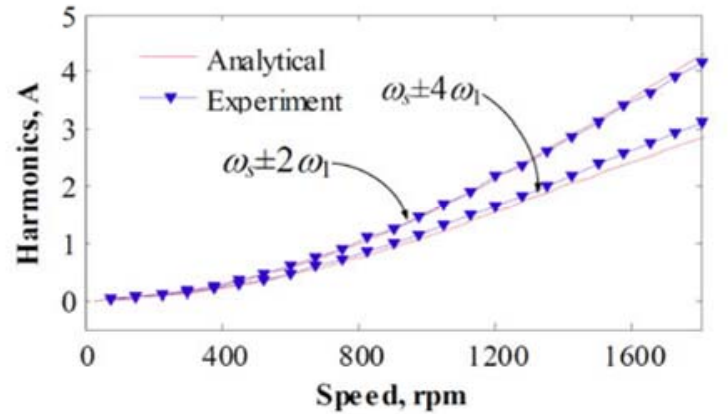

(a)

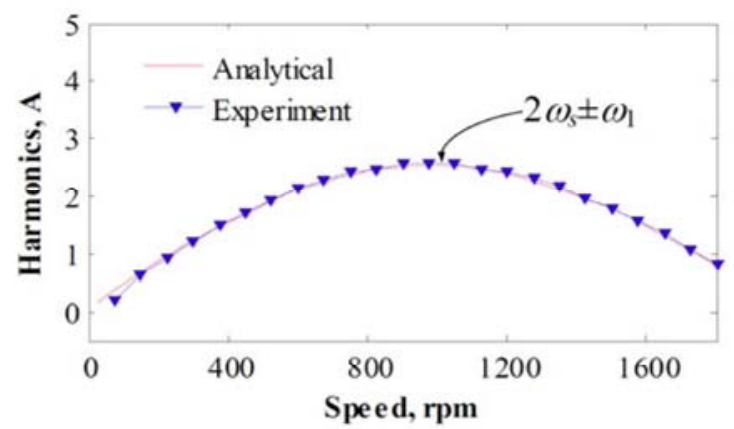

(b)

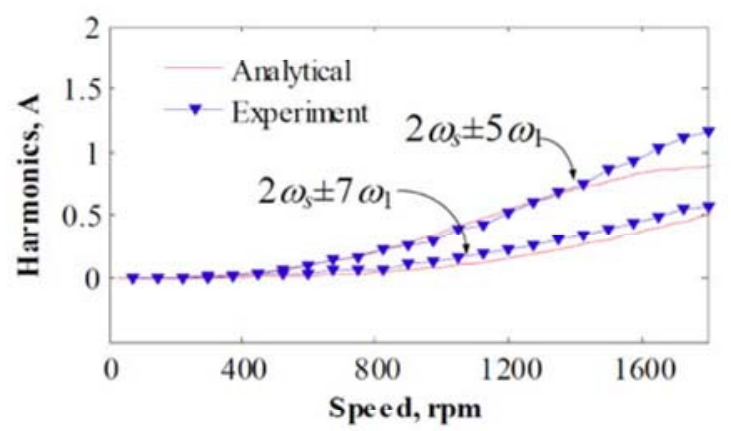

(c)

Fig. 4. Phase current harmonic amplitudes with different speed: (a) $\omega_{s} \pm$ $2 \omega_{1}$ - and $\omega_{s} \pm 4 \omega_{1}$-order harmonics, (b) $2 \omega_{s} \pm \omega_{1}$-order harmonics, and (c) $2 \omega_{s} \pm 5 \omega_{1}$ - and $2 \omega_{s} \pm 7 \omega_{1}$-order harmonics.

voltage harmonics in rotor frame can be summed up as

$$
\begin{aligned}
& u_{d \_2 \omega_{s}}=2 C_{1} \sin \varphi_{0} \cos \left(2 \omega_{s} t\right) \\
& u_{q_{-} 2 \omega_{s}}=-2 C_{1} \cos \varphi_{0} \cos \left(2 \omega_{s} t\right) .
\end{aligned}
$$

On the other hand, the $2 \omega_{s} \pm 6 \omega_{1}$-order voltage harmonics in rotor frame can be expressed as

$$
\begin{aligned}
& u_{d \_2 \omega_{s} \pm 6 \omega_{1}}=U_{d 22_{-} 6} \sin \left( \pm 2 \omega_{s} t+6 \omega_{1} t+\varphi_{d 2 \_6}\right) \\
& u_{q_{-} 2 \omega_{s} \pm 6 \omega_{1}}=U_{q 2 \_6} \sin \left( \pm 2 \omega_{s} t+6 \omega_{1} t+\varphi_{q 2 \_6}\right)
\end{aligned}
$$

where

$$
\begin{aligned}
& U_{d 2 \_6}=\sqrt{C_{5}^{2}+C_{7}^{2}+2 C_{5} C_{7} \cos \left(2 \varphi_{0}\right)} \\
& U_{q 2 \_6}=\sqrt{C_{5}^{2}+C_{7}^{2}-2 C_{5} C_{7} \cos \left(2 \varphi_{0}\right)} .
\end{aligned}
$$

$\varphi_{d 2 \_6}$ and $\varphi_{q 2 \_6}$ can be determined by

$$
\begin{aligned}
& \cos \varphi_{d 2 \_6}=\frac{\left(C_{7}+C_{5}\right) \cos \left(\varphi_{0}\right)}{\sqrt{C_{5}^{2}+C_{7}^{2}+2 C_{5} C_{7} \cos \left(2 \varphi_{0}\right)}} \\
& \sin \varphi_{d 2 \_6}=\frac{\left(C_{7}-C_{5}\right) \sin \left(\varphi_{0}\right)}{\sqrt{C_{5}^{2}+C_{7}^{2}+2 C_{5} C_{7} \cos \left(2 \varphi_{0}\right)}} \\
& \cos \varphi_{q 2 \_6}=\frac{\left(C_{5}+C_{7}\right) \sin \left(\varphi_{0}\right)}{\sqrt{C_{5}^{2}+C_{7}^{2}-2 C_{5} C_{7} \cos \left(2 \varphi_{0}\right)}} \\
& \sin \varphi_{q 2 \_6}=\frac{\left(C_{5}-C_{7}\right) \cos \left(\varphi_{0}\right)}{\sqrt{C_{5}^{2}+C_{7}^{2}-2 C_{5} C_{7} \cos \left(2 \varphi_{0}\right)}} .
\end{aligned}
$$

It can be revealed from the analysis in (19)-(22) that the amplitudes of the second carrier frequency sideband voltage harmonics in the rotor frame are determined by both the modulation ratio and torque angle as well.

\section{Analytical Sideband CURRENT Harmonic Modeling}

The main $d$ and $q$ axis sideband current harmonics can be directly derived in analytical forms from the corresponding voltage harmonic components in the previous Section. Then, the analytical expressions of the sideband current harmonics could be accordingly converted from the rotor frame to the stator frame.

\section{A. $D$ and $Q$ Current Harmonics in Rotor Frame}

In PMSM, the correlation between the voltage vector and current vector can be simply expressed as

$$
\vec{u}_{s}=R_{s} \vec{i}_{s}+L_{s} \frac{d \vec{i}_{s}}{d t}+\omega_{1} \vec{i}_{s} \frac{\partial L_{s}}{\partial \theta} .
$$

As the sideband current harmonic frequencies are normally much higher than the fundamental one and the corresponding harmonic magnetic permeances are very trivial, the last term in the right side of (23) can be neglected. Additionally, the sideband harmonic reactance would normally be much greater than the winding resistance. Therefore, the $\mu$-order harmonic current in steady state can be approximated as

$$
i_{d \mu}=\frac{u_{d \mu}}{j \omega_{\mu} L_{d}} \quad \text { and } \quad i_{q \mu}=\frac{u_{q \mu}}{j \omega_{\mu} L_{q}} .
$$

By substituting the $\omega_{s} \pm \omega_{1}, 2 \omega_{s}$ and $2 \omega_{s} \pm 6 \omega_{1}$ order $d$ and $q$ axis voltage harmonic expressions from (16), (19), and (20) into (24), the corresponding current harmonics can be obtained as

$$
\begin{aligned}
i_{d \omega_{s} \pm 3 \omega_{1}} & =\frac{U_{d 1} E_{d} \sin \left(\omega_{s} t \pm 3 \omega_{1} t \pm \varphi_{d 1}\right)}{2\left(\omega_{s} \pm 3 \omega_{1}\right) L_{d}} \\
i_{q \_\omega_{s} \pm 3 \omega_{1}} & =\frac{\mp U_{q 1} E_{d} \cos \left(\omega_{s} t \pm 3 \omega_{1} t \pm \varphi_{q 1}\right)}{2\left(\omega_{s} \pm 3 \omega_{1}\right) L_{q}} \\
i_{d \_2 \omega_{s}} & =\frac{C_{1} E_{d} \sin \varphi_{0} \sin \left(2 \omega_{s} t\right)}{2 \omega_{s} L_{d}} \\
i_{q \_2 \omega_{s}} & =\frac{-C_{1} E_{d} \cos \varphi_{0} \sin \left(2 \omega_{s} t\right)}{2 \omega_{s} L_{q}}
\end{aligned}
$$




$$
\begin{aligned}
& i_{d \_2 \omega_{s} \pm 6 \omega_{1}}=\frac{-U_{d 2 \_6} E_{d} \cos \left( \pm 2 \omega_{s} t+6 \omega_{1} t+\varphi_{d 2 \_6}\right)}{4\left(\omega_{s} \pm 3 \omega_{1}\right) L_{d}} \\
& i_{q \_2 \omega_{s} \pm 6 \omega_{1}}=\frac{-U_{d 2 \_6} E_{d} \cos \left( \pm 2 \omega_{s} t+6 \omega_{1} t+\varphi_{d 2 \_6}\right)}{4\left(\omega_{s} \pm 3 \omega_{1}\right) L_{q}} .
\end{aligned}
$$

\section{B. Phase Current Harmonics in Stator Frame}

The $\omega_{s} \pm \omega_{1}$-order current harmonics in the rotor frame can be transformed into $\omega_{s} \pm 2 \omega_{1}$-order and $\omega_{s} \pm 4 \omega_{1}$-order phase current harmonics in the stator frame. The amplitudes of the corresponding phase current harmonic components can be derived as

$$
\begin{aligned}
& i_{s_{-}\left(\omega_{s} \pm 2 \omega_{1}\right)}=\frac{E_{d} \sqrt{M_{2}^{2}+N_{1}^{2}+2 M_{2} N_{1} \cos \left(2 \varphi_{0}\right)}}{4\left(\omega_{s} \pm 3 \omega_{1}\right)} \\
& i_{s_{-}\left(\omega_{s} \pm 4 \omega_{1}\right)}=\frac{E_{d} \sqrt{M_{1}^{2}+N_{2}^{2}+2 M_{1} N_{2} \cos \left(2 \varphi_{0}\right)}}{4\left(\omega_{s} \pm 3 \omega_{1}\right)}
\end{aligned}
$$

where

$$
\begin{array}{ll}
M_{1}=\frac{C_{2}}{L_{d}}-\frac{C_{2}}{L_{q}}, & M_{2}=\frac{C_{2}}{L_{d}}+\frac{C_{2}}{L_{q}} \\
N_{1}=\frac{C_{4}}{L_{d}}-\frac{C_{4}}{L_{q}}, & N_{2}=\frac{C_{4}}{L_{d}}+\frac{C_{4}}{L_{q}} .
\end{array}
$$

By inspecting the analytical expressions of the first carrier sideband current harmonics in (28), a relationship between the amplitudes of the $\omega_{s} \pm 2 \omega_{1}$-order and $\omega_{s} \pm 4 \omega_{1}$-order current harmonics can be revealed as

$$
i_{s_{-}\left(\omega_{s} \pm 2 \omega_{1}\right)}^{2}-i_{s_{-}\left(\omega_{s} \pm 4 \omega_{1}\right)}^{2}=\frac{E_{d}^{2}\left(C_{2}^{2}-C_{4}^{2}\right)}{4 L_{d} L_{q}\left(\omega_{s} \pm 3 \omega_{1}\right)^{2}}>0 .
$$

It is quite evident that the amplitudes of the $\omega_{s} \pm 2 \omega_{1}$-order sideband phase current harmonics are always more significant than the $\omega_{s} \pm 4 \omega_{1}$-order ones.

Analogously, the $2 \omega_{s}$ and $2 \omega_{s} \pm 6 \omega_{1}$-order current harmonic in the rotor frame can be converted into $2 \omega_{s} \pm \omega_{1^{-}}, 2 \omega_{s} \pm 5 \omega_{1^{-}}$, and $2 \omega_{s} \pm 7 \omega_{1}$-order harmonics in the stator phase current. The amplitudes of these harmonics can be accordingly derived as

$$
\begin{aligned}
i_{s_{-}\left(2 \omega_{s} \pm \omega_{1}\right)} & =\frac{E_{d} C_{1}}{4 \omega_{s}} \sqrt{\frac{\sin ^{2} \varphi_{0}}{L_{d}^{2}}+\frac{\cos ^{2} \varphi_{0}}{L_{q}^{2}}} \\
i_{s_{-}\left(2 \omega_{s} \pm 5 \omega_{1}\right)} & =\frac{E_{d} \sqrt{M_{4}^{2}+N_{3}^{2}+2 M_{4} N_{3} \cos \left(2 \varphi_{0}\right)}}{8\left(\omega_{s} \pm 3 \omega_{1}\right)} \\
i_{s_{-}\left(2 \omega_{s} \pm 7 \omega_{1}\right)} & =\frac{E_{d} \sqrt{M_{3}^{2}+N_{4}^{2}+2 M_{3} N_{4} \cos \left(2 \varphi_{0}\right)}}{8\left(\omega_{s} \pm 3 \omega_{1}\right)}
\end{aligned}
$$

where

$$
\begin{array}{ll}
M_{3}=\frac{C_{5}}{L_{d}}-\frac{C_{5}}{L_{q}}, & M_{4}=\frac{C_{5}}{L_{d}}+\frac{C_{5}}{L_{q}} \\
N_{3}=\frac{C_{7}}{L_{d}}-\frac{C_{7}}{L_{q}}, & N_{4}=\frac{C_{7}}{L_{d}}+\frac{C_{7}}{L_{q}} .
\end{array}
$$

It can easily be observed that these current harmonics will be torque angle independent in surface mounted PMSM drives in which $L_{d}$ is equal to $L_{q}$.

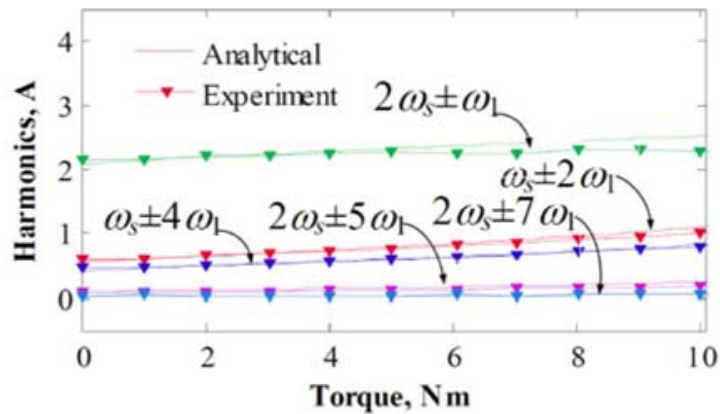

(a)

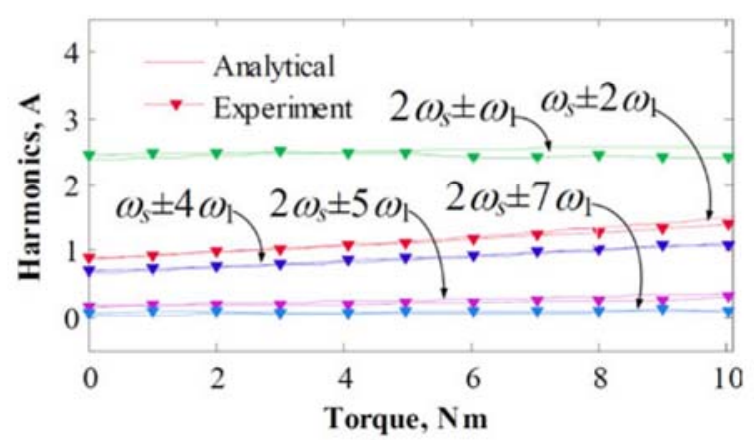

(b)

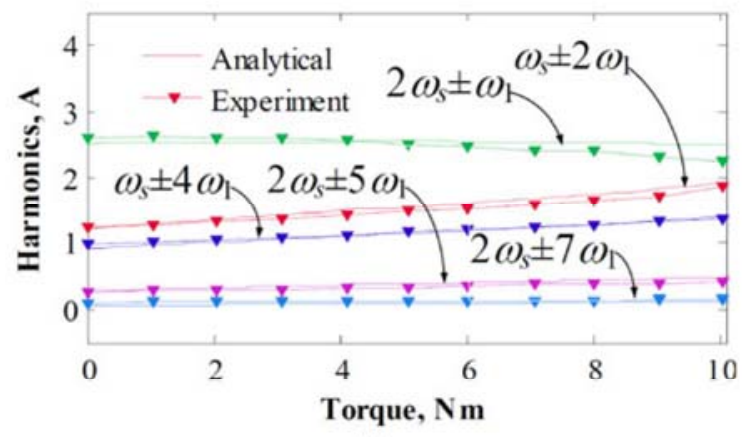

(c)

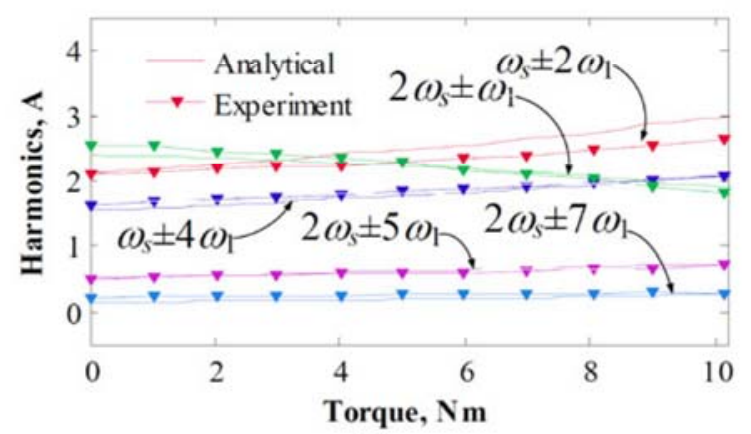

(d)

Fig. 5. Phase current harmonic amplitudes with different load, (a) harmonics under $600 \mathrm{r} / \mathrm{min}$, (b) harmonics under $750 \mathrm{r} / \mathrm{min}$, (c) harmonics under $900 \mathrm{r} / \mathrm{min}$, and (d) harmonics under $1200 \mathrm{r} / \mathrm{min}$.

\section{EXPERIMENTAL VALIDATIONS}

\section{A. Experimental PMSM Drive System}

The experimental tests are carried out in order to validate the analytical models presented in the foregoing sections. The 
PMSM, whose main parameters are given in Table III, is driven by a VSI with SVPWM technique and rotor-flux-oriented vector control $\left(i_{d}=0\right)$ strategy in the experiments. The experimental set up of the IPMSM drive system is depicted in Fig. 2.

The experimental phase current waveform and its harmonic spectrum of the PMSM underrated condition with $5 \mathrm{~N} \cdot \mathrm{m}$ and $1200 \mathrm{r} / \mathrm{min}$ are captured and illustrated in Fig. 3. It can be clearly seen from Fig. 3 that the main sideband phase current harmonics are the $\omega_{s} \pm 2 \omega_{1-}, \omega_{s} \pm 4 \omega_{1}^{-}$, and $2 \omega_{s} \pm$ $\omega_{1}$-order components, and hence, the analytical models are qualitatively validated. Moreover, there are noticeable $2 \omega_{s} \pm$ $5 \omega_{1}$ - and $2 \omega_{s} \pm 7 \omega_{1}$-order harmonics in the second carrier frequency domain. However, the amplitudes of these current harmonics are relatively small.

\section{B. Harmonics Under Different Speed Condition}

As aforementioned, the harmonics are determined by both the modulation ratio and torque angle. In order to validate the analytical models quantitatively, the amplitude variations of the main sideband current harmonics with different modulation ratios are further examined in the proposed PMSM. As the PMSM is with a constant torque load, the modulation ratio of SVPWM is approximately proportional to the machine rotational speed. Therefore, the torque load of the PMSM during experimental test maintains a constant light load of $0.25 \mathrm{~N} \cdot \mathrm{m}$, different rotational speeds (every $75 \mathrm{r} / \mathrm{min}$ ) are implemented in order to achieve various modulation ratios. The corresponding amplitudes of the main sideband current harmonic components from analytical models and experimental tests are derived and compared in Fig. 4. Close agreements between the analytical and experimental results have been demonstrated, which validate that the proposed analytical models can deliver reasonably accurate results with much less computational effort. Furthermore, Fig. 4(a) shows that the amplitudes of the first carrier frequency sideband current harmonics will gradually increase as the modulation ratio rises. Fig. 4(b) reveals that the amplitudes of the $2 \omega_{s} \pm \omega_{1}$-order current harmonics will first increase and reach their peaks, and then start to decrease as the modulation ratio increases. Fig. 4(c) demonstrates that the amplitudes of the $2 \omega_{s} \pm 5 \omega_{1}$-order and $2 \omega_{s} \pm 7 \omega_{1}$-order current harmonics will also gradually rise along with modulation ratio. However, the amplitudes of those particular current harmonics in Fig. 4(c) are relatively small under most of the operational conditions of the machine, hence they are usually negligible.

\section{Harmonics Under Different Load Condition}

According to (28), (31), and (32), the load torque is also an important influence factor which will impact on the modulation ratios and torque angle. In order to validate the analytical models comprehensively, the experimental tests with different load torque under $600,750,900$, and $1200 \mathrm{r} / \mathrm{min}$ are implemented and the phase current are captured every $1 \mathrm{~N} \cdot \mathrm{m}$ from 0 to $10 \mathrm{~N} \cdot \mathrm{m}$.

The corresponding amplitudes of the $\omega_{s} \pm 2 \omega_{1}-, \omega_{s} \pm 4 \omega_{1}$, $2 \omega_{s} \pm \omega_{1-}, 2 \omega_{s} \pm 5 \omega_{1}$, and $2 \omega_{s} \pm 7 \omega_{1}$-order components from analytical models and experimental tests are derived and compared in Fig. 5. Again, close agreements between the analytical and experimental results have been demonstrated. Hence the proposed analytical models are validated with different loads.

\section{CONCLUSION}

Analytical investigations of the sideband voltage and hence current harmonic components in PMSM powered by VSI with regular sampled SVPWM technique have been carried out. The analytical expressions of the sideband harmonics in the first and second carrier frequency domain are developed in both the rotor and stator frames. Moreover, the experimental tests on a prototype IPMSM have been undertaken to validate comprehensively the analytical models under different speed and load torque operational conditions. Based on the analytical equations, the impact factors, such as carrier frequency, electromagnetic parameters, and control parameters can be duly inspected.

The proposed analytical model can be employed to further study the corresponding losses, torque ripple, and radial force wave analytically. The analytical equations can provide intuitive information to promptly assess the effectiveness of different techniques on loss, torque pulsation, and electromagnetic noise reductions. It is always of particular importance to analytically appraise the pros and cons of the technique to be deployed in order to improve the overall performance of the drive system.

\section{REFERENCES}

[1] A. Boglietti, P. Ferraris, M. Lazzari, and M. Pastorelli, "Influence of the inverter characteristics on the iron losses in PWM inverter fed induction motors," in Proc. 30th IEEE IAS Annu. Meeting, vol. 1, Oct. 1995, pp. 637641.

[2] S. Khomfoi, V. Kinnares, and P. Viriya, "Influence of PWM characteristics on the core losses due to harmonic voltages in PWM fed induction motors," in Proc. IEEE Power Eng. Soc. Winter Meeting, vol. 1, 2000, pp. 365-369.

[3] P. Hothongkham and V. Kinnares, "Investigation into harmonic losses in a PWM multilevel cascaded H-bridge inverter fed induction motor," in Proc. Int. Power Electron. Drive Syst. Conf., Nov. 2007, pp. 1043-1048.

[4] K. Basu, J. S. Siva Prasad, and G. Narayanan, "Minimization of torque ripple in PWM AC drives," IEEE Trans. Ind. Electron, vol. 56, no. 2, pp. 553-557, Feb. 2009.

[5] S. Halasz and A. Z. Kohari, "Torque pulsations of multiphase inverter-fed AC motors," in Proc. Int. Power Electron. Motion Control Conf., Sep. 2010, pp. 157-162.

[6] A. K. Wallace, R. Spee, and L. G. Martin, "Current harmonics and acoustic noise in AC adjustable speed drives," in Proc. 23rd IEEE IAS Annu. Meeting, Oct. 1988, vol. 1, pp. 483-488.

[7] J. Besnerais, V. Lanfranchi, M. Hecquet, and P. Brochet, "Characterization and reduction of audible magnetic noise due to PWM supply in induction machines," IEEE Trans. Ind. Electron., vol. 57, no. 4, pp. 1288-1295, Apr. 2010.

[8] J. F. Moynihan, M. G. Egan, and J. M. D. Murphy, "Theoretical spectra of space-vector-modulated waveforms," IEE Proc. Electric Power Appl., vol. 145 , no. 1, pp. 17-24, Jan. 1998.

[9] D. G. Holmes, "A general analytical method for determining the theoretical harmonic components of carrier based PWM strategies," in Proc. 33rd IEEE IAS Annu. Meeting, Oct. 1998, vol. 2, pp. 1207-1214.

[10] H. Deng, L. Helle, Y. Bo, and K. B. Larsen, "A general solution for theoretical harmonic components of carrier based PWM schemes," in Proc. 24th Annu. IEEE Applied Power Electron. Conf., Feb. 2009, pp. 1698-1703.

[11] J. T. Boys and P. G. Handley, "Harmonic analysis of space vector modulated PWM waveforms," IEE Proc. Electric Power Appl., vol. 137, no. 4, 197-204, Jul. 1990.

[12] A. W. Leedy and R. M. Nelms, "Harmonic analysis of a space vector PWM inverter using the method of multiple pulses," in Proc. IEEE Int. Symp. Ind. Electron., Jul. 9-12, 2006, pp. 1182-1187.

[13] H. W. van der Broeck, H.-C. Skudelny, and G. V. Stanke, "Analysis and realization of a pulse width modulator based on voltage-space vectors," IEEE Trans. Ind. Appl, vol. 24, no. 1, pp. 142-150, Jan./Feb. 1988. 
[14] T. A. Sakharuk, A. M. Stankovic, G. Tadmor, and G. Eirea, "Modeling of PWM inverter-supplied AC drives at low switching frequencies," IEEE Trans. Circuits Syst. I, Fundam. Theory Appl., vol. 49, no. 5, pp. 621-631, May 2002.

[15] S. Halasz, G. Csonka, and A. A. H. Hassan, "Generalized harmonic loss curves of AC motors fed from two and three level inverters," in Proc. 22nd Annu. Conf. IEEE Ind. Electron. Soc., Aug. 5-10, 1996, vol. 2, pp. $957-962$.

[16] G. Narayanan and V. T. Ranganathan, "Analytical evaluation of harmonic distortion in PWM AC drive using the notion of stator flux ripple," IEEE Trans. Ind. Electron, vol. 20, no. 2, pp. 466-474, Mar. 2005.

[17] B. P. McGrath, D. G. Holmes, and T. Meynard, "Reduced PWM harmonic distortion for multilevel inverters operating over a wide modulation range," IEEE Trans. Power Electron., vol. 21, no. 4, pp. 941-949, Jul. 2006.

[18] G. Narayanan, D. Zhao, H. K. Krishnamurthy, R. Ayyanar, and V. T. Ranganathan, "Space vector based hybrid PWM techniques for reduced current ripple," IEEE Trans. Power Electron., vol. 55, no. 4, pp. 1614-1626, Apr. 2008.

[19] D. W. Kang and D. S. Hyun, "Simple harmonic analysis method for multicarrier PWM techniques using output phase voltage in multi-level inverter," IEE Proc. Electric Power Appl., vol. 152, no. 2, pp. 157-165, 2005 .

[20] T. Beechner and J. Sun, "Harmonic cancellation under interleaved PWM with harmonic injection," in Proc. IEEE Power Electron. Spec. Conf., Jun. $15-19,2008$, pp. 1515-1521.

[21] L. Accardo, M. Fioretto, G. Giannini, and P. Marino, "Techniques of PWM space vector modulation for the reduction of magnetic acoustic noise in traction motor," in Proc. Int. Symp. Power Electron., Elect. Drives, Autom. Motion, May 23-26, 2006, pp. 1084-1089.

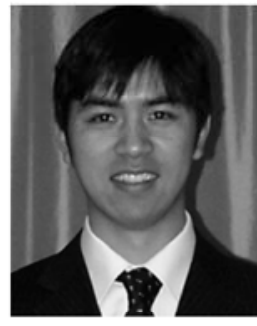

Wenyi Liang was born in Zhejiang, China, 1982. He received the B.Eng. and M.Eng. degrees in electrical engineering from Zhejiang University, Hangzhou, China, in 2004 and 2006, respectively

From 2006 to 2014, he was a Development Engineer in Hangzhou Easitech Corporation, Hangzhou. $\mathrm{He}$ is currently a Research Fellow with the Electric Power and Drives Group, School of Engineering, Cranfield, U.K. His current research interests include design, analysis, and applications of electric machines and drives.

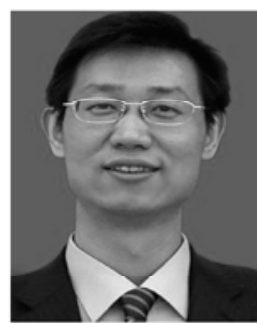

Jianfeng Wang was born in Taiyuan, China, 1977. He received the B.Eng. and M.Eng. degrees in electrical engineering from Taiyuan University of Technology, Taiyuan, China, in 1999 and 2003, respectively.

From 2003 to 2007, he was a Lecturer with the Department of Electric Engineering, Taiyuan University of Technology, Taiyuan, China. Since 2007, he has been with Hangzhou Easitech Corporation, Hangzhou, China. His current research interests include field computation in electric machinery, power electronics, simulation of power circuits, and system

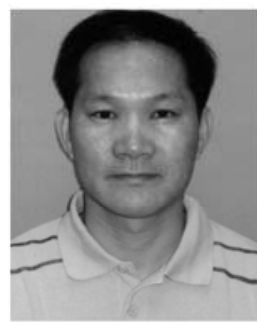

Patrick Chi-Kwong Luk (M'97-SM'10) was born in Hong Kong. He received the M.Phil. degree from the University of Sheffield, Sheffield, U.K., in 1989, and the Ph.D. degree from the University of South Wales, Cardiff, U.K., in 1992, all in electric engineering.

From 1988 to 2002, he held academic positions at the University of Glamorgan; The Robert Gordon University, Aberdeen, U.K.; and the University of Hertfordshire, Hatfield, U.K. Since 2002, he has been with Cranfield University, Cranfield, U.K., where he is currently a Professor in Electrical Engineering. He is currently involved in fundamental and applied research in electric machines and power electronic drives, renewable energy systems, and more-electric architectures in vehicles and aircraft. He is an Associate Editor for the IET Journal for Renewable Power Generation.

Dr. Luk actively volunteers his time as the Chairperson for IEEE UK\&RI Professional Activities, and IEEE UK\&RI Power Electronics Chapter. He is an Associate Editor for the IEEE TRANSACTIONS ON POWER ELECTRONICS and IET Journal for Renewable Power Generation.

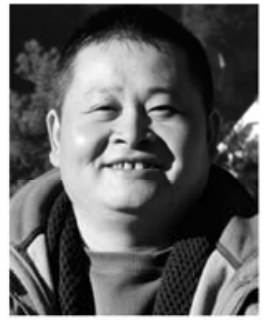

Weizhong Fang (M'05) was born in Hangzhou, China. He received the B.Eng. and Ph.D. degrees in electrical engineering from Zhejiang University, Hangzhou, China, in 1993 and 1998, respectively.

From 2001 to 2005, he was EM Marketing Manager at Ansoft Corp. He is currently the General Manager and the Chief Engineer of Hangzhou Easitech Co. His current research interests include finite element method based design and simulation platform of electric machine and drive systems.

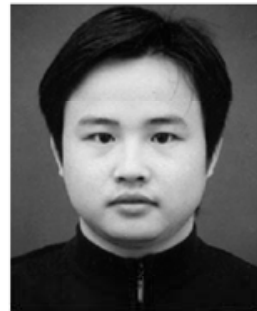

Weizhong Fei (M'12) was born in Zhejiang, China. $\mathrm{He}$ received the B.Eng. and M.Eng. degrees from Zhejiang University, Hangzhou, China, in 2004 and 2006, respectively, and the Ph.D. degree from Cranfield University, Shrivenham, U.K., in 2010, all in electrical engineering.

From 2011 to 2012, he was a Research Associate at the University of Sheffield, Sheffield, U.K. Since 2012, he has been with the School of Engineering, Cranfield University, where he is currently a Lecturer in Clean Energy. His current research interests include design and applications of electric machines and drives. 